\title{
Memberdayakan High Order Thinking Skill (Hots) Melalui Model Scientific Reading Based Project (SRBP) Pada Pembelajaran IPA Bagi Calon Guru Di Era Revolusi Industri 4.0
}

\author{
Kartika Chrysti Suryandari, Sajidan \\ Universitas Sebelas Maret \\ kartika@fkip.uns.ac.id
}

Sejarah Artikel

diterima 18/10/2019

disetujui 09/11/2019

diterbitkan 13/12/2019

\begin{abstract}
The research's high-level thinking skills on aspects of analyzing, evaluating, and creating are needed in everyday life. The purpose of this study is to empower higher-order thinking skills for Kebumen PGSD students using the SRBP learning model. This type of quasi-experimental research with control and treatment classes, the study sample was students in the third semester of 2018 totaling 76 people, who attended the Basic Concepts of Science 2 PGSD Kebumen, FKIP UNS. Data collection techniques pre-test post-test observation, interviews, and questionnaires. Data analysis with parametric statistics with the help of SPSS 21. Testing techniques and assumptions: paired sample t-test the mean difference before and after treatment and independent sample t-test the mean difference between groups continued with the effect size test. The results showed that the ability to think at a high level of analysis was more prominent than evaluation and creation. The implications of the SRBP research model can be applied to basic education levels by modifying literacy sources.

Keywords: SRBP model, high order thinking skills, prospective teachers
\end{abstract}

\section{Abstrak}

Keterampilan berpikir tingkat tinggi penelitian ini pada aspek menganalisis, mengevaluasi dan mencipta dibutuhkan dalam kehidupan sehari-hari. Tujuan penelitian ini adalah memberdayakan keterampilan berpikir tingkat tinggi bagi mahasiswa PGSD Kebumen menggunakan model pembelajaran SRBP. Jenis penelitian quasi eksperimen dengan kelas kontrol dan perlakuan, sampel penelitian adalah mahasiswa semester tiga angkatan tahun 2018 sejumlah 76 orang, yang mengikuti mata kuliah Konsep Dasar IImu Pengetahuan 2 PGSD Kebumen, FKIP UNS. Teknik pengambilan data pre test-post test observasi, wawancara dan kuesioner. Analisis data dengan statistik parametrik dengan bantuan SPSS 21. Teknik dan asumsi pengujian: paired sample t-test untuk beda rerata sebelum dan setelah perlakukan dan independent sample t-test untuk beda rerata antar kelompok dilanjutkan dengan uji effect size. Hasil penelitian menunjukkan bahwa keteramoilan berpikir tingkat tinggi pada aspek menganalisis lebih menonjol daripada evaluasi dan mencipta. Implikasi penelitian model SRBP dapat diterapkan pada jenjang pendidikan dasar dengan memodifikasi sumber literasi.

Kata kunci: model SRBP, high order thinking skill, calon guru 


\section{PENDAHULUAN}

Era revolusi industry 4.0 mengintegrasikan pemanfaatan teknologi dan internet yang mempengaruhi kehidupan manusia pada dunia usaha, industri perilaku masyarakat dan pendidikan. Karakteristik di era revolusi industri meliputi digitalisasi, optimasi, produksi, otomasi dan adaptasi, interaksi antara manusia dengan mesin serta penggunaan teknologi informasi. Revolusi industri 4.0 merupakan cara merubah pola kerja yang mengutamakan pengelolaan data, dengan dengan sistem yang lebih canggih, melalui jaringan Inetworking agar lebih efisiensi. Revolusi industry 4.0 sangat mempengaruhi pendidikan erutama dalam proses pembelajarannya (Kemenristekdikti,2018).

Pendidikan dan proses pembelajarannya menitikberatkan untuk mengeksplorasi kemampuan peserta didik berkompetensi di bidangnya agar diterima dengan baik di sector industri. Hal tersebut sejalan dengan program pemerintah yang berkaitan dengan lima elemen penting yang menumbuhkan ekonomi dan daya saing bangsa di era Revolusi Industri 4.0, yaitu: 1) penerapan model pembelajaran yang lebih inovatif, pengembangan kurikulum pembelajaran, dan peningkatkan kompetensi mahasiswa dalam hal data Information Technology (IT), Operational Technology (OT), Internet of Things (IOT), dan Big Data Analitic, 2) perubahan aturan dalam perguruan tinggi yang disesuaikan dengan pembelajaran abad 21, untuk mengembangkan berbagai disiplin ilmu sesuai dengan program yang diperlukan, 3) peningkatan sumber daya manusia terutama dosen dan peneliti agar lebih handal, 4) pengembangan penelitian dan pengabdian masyarakat secara kualitas dan kuantitas, 5) inovasi di bidang industri (Kemenristekdikti,2018).

Upaya untuk meningkatkan sumber daya manusia adalah dengan memberdayakan kemampuan berpikir tingkat tinggi atau Higher Order Thinking Skills (HOTs). Menurut taksonomi Bloom HOTs meliputi aspek berpikir dalam aspek menganalisis, mengevaluasi, dan mencipta. Pemberdayaan HOTs bagi peserta didik merupakan aspek penting dalam peningkatan kecakapan hidup (Rooney \& Caitriona, 2012:6). HOTs adalah proses berpikir yang menempati jengjang kognitif lebih tinggi, yang penting untuk selalu dilatih pada peserta didik. Aspek HOTs meliputi problem solving atau kemampuan pemecahan masalah, kemampuan berpikir kreatif,berpikir kritis,kemam puan berargumen, dan kemampuan mengambil keputusan (Nachiappan, Damahuri, Ganaprakasam, \& Suffian, 2018).

Dalam taksonomi Bloom jenjang kognitif untuk mengukur kemampuan berpikir tingkat tinggi dengan indikator menganalisiss(C4) yaitu kemampuan memisahkan konsep menjadi beberapa komponen dan dipadukan untuk mendapat pengetahuan yangmutuh, mengevaluasi (C5) yaitu kemampuan menilai sesuatu berdasarkan norma, kriteria atau patokan tertentu, dan mencipta (C6) yaitu kemampuan memadukan unsur-unsur menjadi sesuatu bentuk baru yang utuh dan 
luas, atau membuat suatu yang orisinil (Krathwohl, 2002). Pembelajaran IPA di era Revolusi Industri 4.00 menitikberakan peserta didik dilatih untuk peka terhadap perubahan fenomena alam. IPA sebagai ilmu pengetahuan yang mempelajari fenomena alam berdasarkan fakta, kejadian dan hubungan sebab akibat. Konsep IPA berhubungan dengan aktivitas dalam kehidupan sehari-harii yang berkaitan dengan alam (Abell, Rogers, Hanuscin, Lee, \& Gagnon, 2009).

Pembelajaran Konsep Dasar IPA dikaji secara holistik terdiri dari beberapa aspek mencakup kesatuan pengetahuan (body knowledge), cara berpikir (thinking of ways), cara penyelidikan (ways of investigation) yang berkaitan dengan teknologi dan masyarakat. Aktivitas dalam IPA melibatkan mahasiswa mempunyai rasa ingin tahu tinggi, menginvestigasi, dan mengemukakan gagasan-gagasan tentang peristiwa yang diamati (Kind, 2015). Setiap konten IPA memiliki karakteristik yang khas, maka berbeda pula cara mengajarkannya ( Koehler \& Mishra, 2009; Schneider \& Plasman, 2011). Rasa ingin tahu adalah tindakan yang berupaya untuk mengetahui lebih dalam apa yang dilihat dan dipelajari. Rasa ingin tahu membuat peserta didik peka terhadap fenomena alam, dan berkaitan dengan kemampuan berpikir tingkat tinggi (Saputri, Sajidan, Rinanto, Afandi, 2019).

$\begin{array}{ccc}\text { Menurut } & \text { standar } & \text { yang } \\ \text { ditetapkan } & \text { Program } & \text { for }\end{array}$

International Student Assessment

(PISA), menunjukkan keterampilan berpikir tingkat tinggi peserta didik Indonesia jika ditinjau dari hasil masih tergolong rendah. Berdasarkan suver studi literasi literasi sains, kemampuan berpikir HOTs peserta didik Indonesia berada pada peringkat berada diperingkat 69 dari 75 negara peserta (ODEC, 2016). Berdasarkan pengamatan mahasiswa PGSD sebagai calon guru belum dibiasakan untuk berpikir tingkat tinggi. Hal ini dapat diobservasi dari berapa aspek antara lain 1) ketika menjawab pertanyaan dalam pembelajaran hanya mampu menjelaskan dari satu sudut pandang dan tidak dapat menguraikan menjadi komponen yang lebih detail, 2) kemampuan membuat soal kognitif sebatas pada jenjang C1 (menyebutkan) dan C2 (menjelaskan), 3) pendapat/gagasan masih bersifat normative belum memunculkan ide yang unik atau original (Suryandari, Sajidan, Rahardjo, Prasetyo, Fatimah, 2017).

Model Scientific Reading Based Project (SRBP) adalah model pembelajaran inovatif berdasarkan pembelajaran inkuiri yang dikembangkan melalui sejumlah kajian pustaka tentang teori-teori belajar dan implementasi di lapangan. Model ini dapat digunakan untuk melatih aspek keterampilan berpikir tingkat tinggi mahasiswa melalui aktivitas enam sintaksis. Sintak model SRBP meliputi 1) orientation, 2) scientific reading, 3) design of project, 4) progress of project, 5) analysis, 6) discussion and communication (Suryandari, Sajidan, Rahardjo, Prasetyo, 2019). Model SRBP menitikberatkan proyek dan riset dalam proses pembelajaraanya berdasarkan aktivitas scientific reading atau pengamatan terhadap fenomena alam, kemudian dikaitkan dengan konsep IPA dengan sumber literatur ilmiah. Model pembelajaran SRBP didasari kajian filosofi konstruktivisme yang meliputi empat aspek, yaitu pembelajaran 
yang membangun pengetahuan peserta

pembelajaran dengan mengemban

gkan prior knowledge, pembelajaran yang menekankan proses interaksi sosial dan pembelajaran bermakna yang diperoleh melalui pengalaman nyata (Saputri, Sajidan, Rinanto, Afandi, 2019; Johnson, 2006). Pembelajaran menggunakan model SRBP dalam pelaksanaannya menekankan aspek-aspek soft skills seperti penelitian, membaca komprehensif, kemampuan kolaboratif dan komunikatif. Aspek soft skills tersebut dibutuhkan untuk menunjang pembelajaran dengan model SRBP. Kemampuan kolaboratif dan kerjasama dengan tujuan saling bertukar pikiran atau berdiskusi dalam menyelesaikan permasalahan merupakan ciri khusus pembelajaran yang bersifat proyek

(Quintana \& Fernández, 2015). Pembelajaran yang bersifat proyek dapat meningkatkan keterampilan berpikir kritis dan kreatif (Suryandari, Sajidan, Rahardjo, Prasetyo, 2017)

Beberapa penelitian model pembelajaran dengan menekankan proyek adalah Project Based Learning (PBL) yang dilakukan berdasarkan pendapat Lucas (Guilford \& Hoepfner, 1971). Model pembelajaran PBL dalam sintaknya menekankan pengembangan keterampilan inkuiri untuk membuat proyek. Sintak model PBL tidak menekankan aktivitas membaca dalam menyelesaikan proyek. Model SRBP memiliki kebaruan pada langkah pembelajarannya yang menekankan langkah scientific reading dalam pembelajarannya menyelesaikan

Tujuan penelitian ini adalah:

memberdayakan kemampuan berpikir tingkat tinggi /HOTs pada aspek menganalisis, mengevaluasi, dan mencipta melalui model SRBP pada mahasiswa

PGSD.

\section{METODOLOGI}

Metode penelitian adalah quasi eksperimen dengan 2 kelas perlakuan dan satu kelas kontrol. dengan pemberian pretest dan posttes. Waktu penelitian dilaksanakan selama dua bulan dengan materi Gelombang Cahaya. Sampel penelitian pada mahasiswa semester 3 Angkatan 2017/2018 yang terdiri 3 kelas sejumlah 121 mahasiswa. Kelas A dan $B$ adalah kelas perlakuan dengan model SRBP sejumlah 81 orang dan kontrol menggunakan metode inkuiri dengan jumlah 40 orang. Penilaian keterampilan berpikir tingkat tinggi meliputi aspek 1) analisis, 2) evaluasi dan 3)mencipta. Teknik pengambilan data secara observasi, checklist dan pretes-postes untuk mengetahui $\mathrm{N}$-gain kemudian dihitung menggunakan

rumus:

$$
\text { gain }=\frac{\text { skor postes }- \text { skorpretes }}{\text { skormax }- \text { skorpretes }} \quad(\text { Hake, 1999 })
$$

Menurut Hake (1999) N-gain dengan skor $0,70<\mathrm{g}<1,00$ kategori tinggi, $0,30<\mathrm{g}<0,70$ kategori sedang, $0,00<\mathrm{g}<0,30$ kategori rendah. Analisis data dengan statistik diskriptif quantitative. Tes normalitas dengan Kolmogorov smirnov, homogenitas samel dengan Levena 
tes, Uji ANCOVA dengan bantuan SPSS 22 (Ghozali, 2006), dan Uji effect size dengan interpretasi menurut bahwa skor 0,2 - 0,5 (kecil),
$0,5-0,8$ (sedang), dan $>0,8$ (tinggi) Hedges (1981), Cohen (1988), dan Glass (1976) menggunakan Rstat Effect Size kalkulator.

\section{HASIL DAN PEMBAHASAN}

Dari hasil analisis statistik Gain. Tabel 1 menunjukkan N-Gain diskriptif diperoleh hasil pada kelas dengan model SRBP kemampuan berpikir tingkat tinggi dengan skor 0,67 kriteria medium dan pada kelas menggunakan model kontrol skor 0,35 kriteria rendah SRBP dan kontrol diperoleh skor N- (Hake, 1999).

Tabel 1. Rerata skor dan $\mathrm{N}$-gain aspek berpikir tingkat tinggi

\begin{tabular}{lrrrlrr}
\hline Kelas & Jenis tes & Mean & Gain score & Kriteria & F & Sig \\
\hline SRBP & Pretes & 57,43 & 0,67 & Medium & 14,80 & .000 \\
& Postes & 83.91 & & & & \\
\multirow{2}{*}{ Kontrol } & Pretes & 55.41 & 0,35 & Rendah & & \\
& Postes & 61.25 & & & & \\
\hline
\end{tabular}

Rerata menunjukkan skor $\mathrm{N}$ - berpikir tingkat tinggi/HOTS memiliki Gain tinggi bahwa model SRBP dapat perbedaan yang signifikan antara diterapkan untuk menghitung model pembelajaan SRBP dan keterampilan berpikir tingkat tinggi. kontrol.

Setelah dilakukan uji $\mathrm{t}$ keterampilan

Tabel 2. Analisis keefektifan model dengan uji effect size

\begin{tabular}{crrrrrr}
\hline Kelas & Rerata & STD & Cohen's d & Hedge's g & Glass's & Kriteria \\
\hline SRBP & 83,92 & 0,125 & 0,782 & 0,789 & 0,779 & Tinggi \\
Kontrol & 61,25 & & & & & \\
\hline
\end{tabular}

Analisis keefektifan model efektif memberdayakan berpikir SRBP dengan uji lanjut effect size tingkat tinggi. Untuk mengetahui menurut Cohen's d skor 0,782, efektifitas model pembelajaran Hedge's skor 0,789 dan Glass's skor menggunakan uji lanjut yaitu effect 0,779 dengan kriteria tinggi. Hal ini size (Tabel 2) menunjukkan bahwa model SRBP 


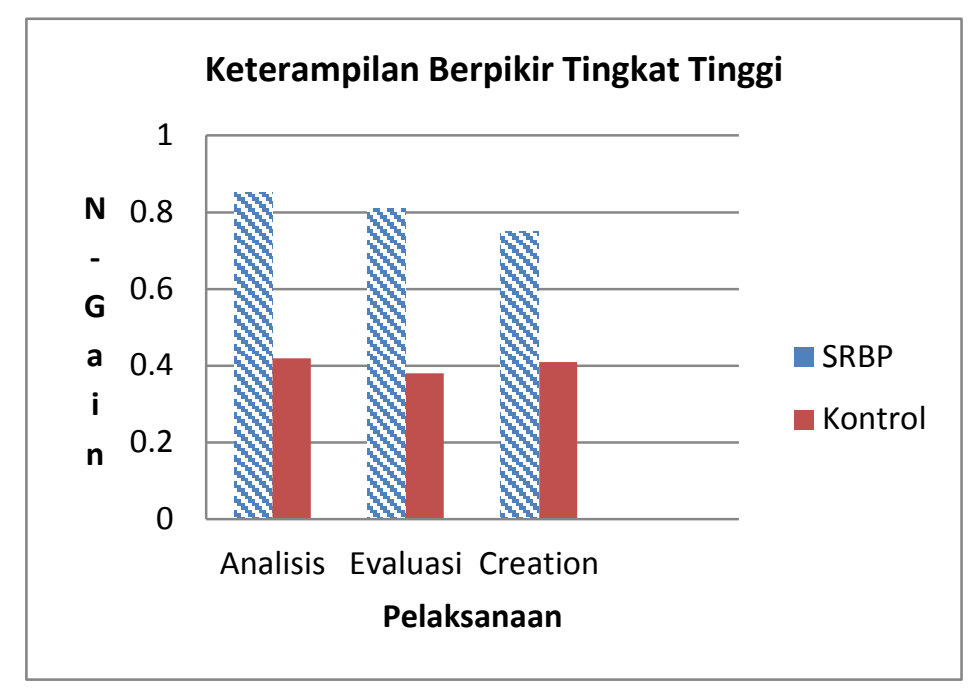

Gambar 1. Perbandingan skor N-gain keterampilan HOTs model SRBP dan kontrol

Jika ditinjau dari setiap aspek berpikir HOTs yang meliputi analisis menunjukkan N-Gain tertinggi dengan skor 0,82 , diikuti evaluasi 0,80 dan kreasi 0,78 . Keterampilan berpikir tingkat tinggi pada kelas model SRBP lebih baik daripada kontrol. Aktivitas HOTs kaitannya dengan pembelajaran IPA mahasiswa dilatih untuk menganalisis data praktikum, dan menganalisis fenomena alam yang berkaitan dengan konsep IPA. Kemampuan menganalisis pada dengan $\mathrm{N}$-gain 0,82. Model SRBP dapat meningkatkan kemampuan kognitif siswa lebih baik dibandingkan dengan kontrol. Pada model SRBP tersirat langkah inkuiri yang terintegrasi pada seluruh sintaks. Model SRBP memiliki sintak yaitu analysis. Pada sintak tersebut mahasiswa dituntut untuk menggunakan seluruh indra yang dimiliki, pikiran, dan hati yang siap untuk menemukan pengetahuan. Keterlibatan mahasiswa secara langsung dalam membangun pengetahuannya sendiri mendorong berkembangnya kemampuan analisis mahasiswa. Menurut Bloom analisis merupakan tingkat keempat dalam keterampilan berpikir tingkat tinggi (HOTs). Analisis meliputi prosesproses kognitif membedakan, mengorganisasi, dan memberikan atribut. Tahapan proses analisis tersebut harus berurutan yakni sebelum mahasiswa melakukan proses memberikan atribut, terlebih dahulu harus melalui proses membedakan dan mengorganisasikan (Anderson, \& Krathwohl, 2010).

Pada tahap evaluasi peserta didik dilatih untuk menilai atau mengkritisi proyek yang telah dibuat, sebagai bagian dari tahapan kegiatan pembelajaran. Aspek evaluasi termasuk jenjang kognitif C5 pada taksonomi Bloom, dengan kesulitan lebih tinggi daripada $\mathrm{C} 4$. Oleh karena itu skor C5 mengalami penurunan yaitu 0,80 . Aspek evaluasi proses menekankan pada evaluasi pengelolaan proyek berupa pembuatan alat peraga IPA SD dari barang bekas dengan materi Gelombang Cahaya, yang dilaksanakan oleh tim kerja. Aspek evaluasi ditekankan pada kelebihan dan kekurangan proses penyelesaian 
proyek, tujuan proyek dan manfaat produk yang dihasilkan. Evaluasi hasil proyek dilaksanakan dengan diskusi antara anggota kelompok. Evaluasi dapat juga diukur menggunakan tes untuk melakukan pengukuran hasil belajar sebagai prestasi belajar, dalam hal ini adalah penguasaan kompetensi oleh setiap mahasiswa. Aktivitas evaluasi membutuhkan kemampuan matakognisi untuk membiasakan berpikir secara hierarkis membuat keputusan dan memecahkan masalah (Bensley \& Spero, 2014).

Kemampuan untuk berpikir orisinil menghasilkan skor yang paling rendah 0,78 dibandingkan dengan skor aspek lainnya. Ide /gagasan mahasiswa bersifat normative kurang menhasilkan ide yang unik. Kemampuan berpikir untuk menghasilkan gagasan/ide yang unik atau tidak umum merupakan berpikir orisinil /Originality (keaslian). Kriteria berpikir orisinil mengacu pada keunikan ide/gagasan dan respon yang diberika peserta didik. Orisinalitas yang ditunjukkan oleh sebuah respon yang tidak biasa, unik dan jarang terjadi. Berfikir untuk memberikan solusi juga memberikan stimulasi ide-ide orisinil (Kind, 2015). Jenis pertanyaanpertanyaan yang digunakan untuk menguji kemampuan ini adalah penggunaan yang menarik dari objekobjek umum. Gagasan yang original dapat distimulasi melalui aktivitas observasi atau pertanyaan stimulan. Gagasan tersebut dapat berupa : (1) mendesain sebuah alat peraga pembelajaran IPA impian masa depan; (2) memikirkan upaya untuk meningkatkan kualitas produk dari proyek. Namun demikian jawaban peserta didik masih tergolong standar dan belum memunculkan ide yang unik (Afandi \& Sajidan, 2017).

Kemampuan berpikir tingkat tinggi perlu dilatih/diasah secara terus menerus dalam menyelesaikan permasalahan. Melalui keterampilan berpikir yang terasah maka dapat mengambil menganalisis dan mengambil kesimpulan dengan tepat. Ide / gagasann baru perlu distimulasi melalui pernyataan atau pengamatan pada saat diskusi kepada peserta didik. Kemampuan berpikir sintesis/mencipta dapat diwujudkan melalui penugasan untuk membuat peta konsep atau alat peraga pembelajaran IPA yang inovatif, laporan praktikum atau gambar. Berpikir inferensi ditampilkan dalam membuat kesimpulan berdasarkan pengamatan atau diskusi dalam pembelajaran. Untuk berpikir sistematis terlebih dulu harus dapat berpikir analisis. Selanjutnya diperlukan kemampuan berpikir logis dalam mengambil kesimpulan terhadap suatu situasi (Cohen, 1988).

Lingkungan keluarga sangat berpengaruh terhadap perkembangan pemikiran kritis dan kreatif seseorang. Keterlibatan dan keterbukaan sikap orang tua dan kebebasan yang diberikan keluarga untuk melakukan eksplorasi. Lingkungan kampus juga berpengaruh terhadap perkembangan berpikir kritis dan kreatif khususnya penerapan model pembelajaran. Pendekatan dan model pembelajaran yang membentuk lingkungan kreatif, belajar aktif, konstruktivistik, kolaboratif dan berinovasi (Ulger, 2016). Interaksi dosen dengan mahasiswa, antar mahasiswa sera sarana prasarana berpengaruh dalam mengembangkan kreativitas. interaksi sosial seperti persaingan, kerjasama, pertentangan dan kekuasaan 
menstimulasi keterampilan berpikir kritis dan kreatif. Keterampilan berpikir HOTs menghasilkan kreativitas. Menurut Rhodes kreativitas ditinjau dari pribadi (person), proses (process), lingkungan (press) dan produk (product) dikenal dengan 4P sebagai komponen esensial (Runco, 2004; Hasirci \& Demirkan, 2003).

Menurut Puccio, Mance \& Murdock (2011) keterampilan berpikir HOTs memerlukan dukungan psikologis. Kebebasan dan keamanan psikologis dapat dilakukan dengan memberi kesempatan individu untuk mengungkapkan perasaan dan pikirannya. Kondisi psikologis menurut Semiawan (1994) diperoleh apabila 1) peserta didik saling menerima apa adanya bahwa setiap orang pada dasarnya mampu dan baik, 2) suasana belajar tenteram tidak ada ancaman, 3) saling memahami dan bertoleransi. Demikian juga lingkungan masyarakat yang sehat dan sejahtera akan memupuk kreativitas. Kemampuan individu tidak lepas dari pengaruh kebudayaan dan masyarakat (Munandar, 2009).

\section{SIMPULAN}

Model Scientific Reading Based kreasi. Rekomendasi dari penelitian Project (SRBP) dapat yaitu model SRBP dapat diterapkan memberdayakan keterampilan berpikir pada jenjang pendidikan dasar tingkat tinggi dengan skor tertinggi dengan sumber belajar disesuaikan pada aspek analisis, evaluasi dan dengan karakteristik siswa

\section{DAFTAR PUSTAKA}

Abell, S. K., Rogers, M. A. P., Hanuscin, D. L., Lee, M. H., \& Gagnon, M. J. (2009). Preparing the next generation of science teacher educators: A model for developing PCK for teaching science teachers. Journal of Science Teacher Education, 20(1), $\quad$ 77-93. https://doi.org/10.1007/s10972008-9115-6

Afandi \& Sajidan (2017). Stimulating Keterampilan Berpikir Tingkat Tinggi: Konsep dan Implementasinya Dalam Pembelajaran Abad 21. (Stimulating Higher Order Thinking Skill: The Concept and Its Implementation in $21^{\text {st }}$ Century Learning). Surakarta: UNS Press.
Cohen, J. (1988). Statistical power analysis for the behavioral sciences (2nd edition). Hillsdale, NJ: Erlbaum.

Glass, G.V. (1976). Primary, secondary, and meta-analysis of research.

Educational Researcher, 5(10). 3-8.

Guilford, J. P., \& Hoepfner, R. (1971). The analysis of intelligence. New York: McGraw-Hill Book Company.

Hake, R.R. (1999). Analyzing change/gain score. CA,USA: Indiana University.

Hedges, L.V. (1981).

Distribution Theory for Glass Estimator of Effect Size and Related Estimators. Journal of Educational Statistics, 6 (2), 
107-128.Johnson,C.

(2006).

Effective profesional

development and change in

practise: bariers science

teachers encounter and

implications for reform. School

Science and Mathematics 106 (3) : 150

Kind, V. (2015). Preservice Science Teachers' Science

Teaching Orientations and Beliefs About Science. Science Education. https://doi.org/10.1002/sce.2119 4

Koehler, M. J., \& Mishra, P. (2009). What Is Technological Pedagogical Content

Knowledge?

Contemporary Issues in

Technology and

Teacher Education, 9(1), 60-70. https://doi.org/10.1016/j.comped u.2010.07.009

Krathwohl, D. R. (2002). A revision of Bloom's taxonomy:

An overview. Theory into practice 41(4), 212-218.

Nachiappan, S., Damahuri, A. A., Ganaprakasam, C., \& Suffian, S. (2018). Application Of Higher Order Thinking Skills ( Hots ) In Teaching And Learning Through Communication Component And Spiritual , Attitudes And Values Component In Preschool Faculty of Human Development, Sultan Idris Education University.

OECD.(2016). PISA 2015 result in focus. PISA: OECD Publishing. Partnership

Rooney, Caitriona. (2012). How am I Using Inquiry-Based Learning to Improve My Practice and to Encourage Higher Order Thinking Among My Students of
Mathematics. Educational Journal.

Schneider, R. M., \& Plasman, K. (2011). Science Teacher Learning Progressions: A Review of Science Teachers' Pedagogical Content Knowledge Development. Review of Educational Research, 81(4), 530-565.

https://doi.org/10.3102/00346543 11423382

Suryandari, K.C., Sajidan, Rahardjo, S.B., Prasetyo,Z.K. (2017). Effectiveness of Project Based Learning on Empowerment Critical Thinking Skill toward Preservice Teacher on Primary Teacher Education Program. Advances in Social Science, Education And Humanities Research (ASSEHR), Vol 158, International Conference on Teacher Training And Education 2017 (ICTTE, 2017).

Suryandari, K.C., Sajidan, Rahardjo, S.B., Prasetyo,Z.K. Fatimah,S. (2017). The Analysis of High Order Thinking Skill (HOTs) on Science Learning Uses Project Based Learning Model Toward Preservice Teacher in Primary Teacher Education Program. Proceeding The $1^{\text {st }}$ International Conference on Educational Sceinces. Vol.1: ICES,ISBN 978-989-758-314-8, pp 97103.DOI:10.5220/000703660097 0103. Bandung. SciTePress

Suryandari, K.C., Sajidan, Rahardjo, S.B., Prasetyo,Z.K. (2019). Model Scientific Reading Based Project Dalam Pemberdayaan Keterampilan Berpikir Kritis dan Kreatif. Widya Sari Press. Salatiga. ISBN 978-602-697761-8. 
Widodo, T \& Kadarwati, S. 2013.

Meningkatkan Hasil Belajar High Order Thinking

Berorientasi Pembentukan

Berbasis Pemecahan

Karakter Siswa.

Cakrawala

Masalah Untuk

Pendidikan 32(1), 161-171. 